\title{
TU/e EmonONEN

\section{AES and SIMS of carbonaceous adsorbate layers on Pt, Rh, and PtRh}

Citation for published version (APA):

van Langeveld, D., \& Niemantsverdriet, J. W. (1986). AES and SIMS of carbonaceous adsorbate layers on Pt, $\mathrm{Rh}$, and PtRh. Surface and Interface Analysis, 9(4), 215-219. https://doi.org/10.1002/sia.740090404

DOI:

10.1002/sia.740090404

Document status and date:

Published: 01/01/1986

\section{Document Version:}

Publisher's PDF, also known as Version of Record (includes final page, issue and volume numbers)

\section{Please check the document version of this publication:}

- A submitted manuscript is the version of the article upon submission and before peer-review. There can be important differences between the submitted version and the official published version of record. People interested in the research are advised to contact the author for the final version of the publication, or visit the $\mathrm{DOI}$ to the publisher's website.

- The final author version and the galley proof are versions of the publication after peer review.

- The final published version features the final layout of the paper including the volume, issue and page numbers.

Link to publication

\section{General rights}

Copyright and moral rights for the publications made accessible in the public portal are retained by the authors and/or other copyright owners and it is a condition of accessing publications that users recognise and abide by the legal requirements associated with these rights.

- Users may download and print one copy of any publication from the public portal for the purpose of private study or research.

- You may not further distribute the material or use it for any profit-making activity or commercial gain

- You may freely distribute the URL identifying the publication in the public portal.

If the publication is distributed under the terms of Article 25fa of the Dutch Copyright Act, indicated by the "Taverne" license above, please follow below link for the End User Agreement:

www.tue.nl/taverne

Take down policy

If you believe that this document breaches copyright please contact us at:

openaccess@tue.nl

providing details and we will investigate your claim. 


\title{
AES and SIMS of Carbonaceous Adsorbate Layers on Pt, Rh, and PtRh
}

\author{
A.D. van Langeveld *and J.W. Niemantsverdriet $\dagger$ \\ ${ }^{*}$ Department of Physics and †Laboratory of Inorganic Chemistry, Eindhoven University of Technology, $5600 \mathrm{MB}$ \\ Eindhoven, The Netherlands
}

\begin{abstract}
Carbonaceous adsorbate layers on polycrystalline $P t, R h$, and $P t R h$, formed from $\mathrm{C}_{2} \mathrm{H}_{4}$ at different temperatures, have been investigated by AES and SIMS. Information on the properties of the carbon has been derived from the fine structure of the carbon Auger peak. SIMS spectra of positive and negative ions in the 12-26 mass range exhibit great sensitivity for the nature of the carbonaceous deposits and reveal the influence of the substrate. Auger spectra indicate that Pt segregates to the surface of the clean PtRh alloy.
\end{abstract}

\section{INTRODUCTION}

Carbonaceous layers form an essential component of working catalysts in hydrocarbon reactions, since they affect catalytic activity, selectivity and stability. These layers are formed immediately when hydrocarbons are passed over the catalyst. The nature of the carbonaceous deposit depends on the substrate and the temperature at which it has been formed.

In the case of $\mathrm{Pt}$, three temperature regimes can be distinguished. ${ }^{1}$ At low temperatures, $<340 \mathrm{~K}$, hydrocarbons are reversibly adsorbed and can be removed by heating. At intermediate temperatures, $340-700 \mathrm{~K}$, the Pt catalyst is readily covered by hydrocarbons which transform into a layer of reactive $\mathrm{C}_{x} \mathrm{H}_{y}$ fragments. These species play an important role in determining the activity and the selectivity of the working Pt catalyst. At high temperatures, above 700 $\mathrm{K}$, the hydrocarbons transform into inactive, graphitic layers which poison the catalyst. AES has successfully been applied to characterize gaseous hydrocarbons $s^{2,3}$ and carbonaceous adsorbate layers on several metals. ${ }^{4}$

${ }_{8}$ Previous work on $\mathrm{Pt}$ and $\mathrm{Rh}$ revealed significant differences in the nature of the carbon species formed on these metals. ${ }^{8}$

SIMS has been applied to study the interaction of hydrocarbons with $\mathrm{Ni}$ and $\mathrm{Ru} .{ }^{9-13}$ To the best of our knowledge, a comparative SIMS investigation of carbonaceous layers on $\mathrm{Pt}, \mathrm{Rh}$, and $\mathrm{PtRh}$ has not been described in the literature.

In this paper we report an investigation by means of AES and SIMS of carbonaceous layers formed by bringing polycrystalline foils of $\mathrm{Pt}, \mathrm{Rh}$, and $\mathrm{PtRh}$ in contact with $\mathrm{C}_{2} \mathrm{H}_{4}$ at three different temperatures, which represent the regimes of hydrocarbon interaction with $\mathrm{Pt}$ discussed above. The results show that SIMS spectra of hydrocarbon fragments are sensitive indicators of the state of the carbonaceous deposit.

\section{EXPERIMENTAL}

The experiments were carried out in an XPS/AES/ SIMS spectrometer (Perkin--Elmer, PHI model 550), equipped with a double-pass cylindrical mirror analyzer and a PHI 2100 specimen introduction/reaction chamber. The base pressure of the UHV chamber is usually $2.10^{-10}$ Torr. In the present experiments, however, pressures were typically in the low $10^{-9}$ Torr range, due to the frequent transfer of the sample between the UHV and the reaction chamber. The base pressure of the latter was $1.10^{-7}$ Torr, obtained with a turbomolucular pump (Pfeiffer, TSU 110).

Auger spectra were measured in differential mode by using a $4.5 \mu \mathrm{A}$ beam of $2 \mathrm{keV}$ electrons, with a spot diameter of $0.5 \mathrm{~mm}$. All spectra were measured in duplo at a scanning rate of $2 \mathrm{eVs}^{-1}$ and a modulation amplitude of $2 \mathrm{eV}$. Each spectrum shown is the sum of two scans. Evidence for electronbeam-induced damage of the adsorbate layer has not been observed.

Static SIMS spectra were measured by using a $50 \mathrm{nA}$ beam of $1 \mathrm{keV} \mathrm{Ar}{ }^{+}$ions from a differentially pumped ion gun (PHI model 04-30) and a UTI 100C quadrupole mass spectrometer. Each sample was analyzed by measuring a positive SIMS spectrum for 60 $\mathrm{s}$, followed by a negative spectrum also for $60 \mathrm{~s}$. The total exposure of the sample during the SIMS experiments was 3.8.10 $0^{13} \mathrm{Ar}^{+}$ions $\mathrm{cm}^{-2}$.

Data acquisition, storage, and instrument control were carried out with a Digital PDP 11/04 computer.

The samples consisted of a polycrystalline foil (specpure quality) of about $15 \times 5 \times 0.1 \mathrm{~mm}$, spotwelded onto a tantalum hairpin. The temperature was monitored by a chromel-alumel thermocouple spotwelded onto the back of the foil. The cleaning procedure consisted of repeated cycles of sputtering with $5 \mathrm{keV} \mathrm{Ar}^{+}$ions and annealing at $1000 \mathrm{~K}$, until no more contaminants could be detected by AES. Finally, 
the samples were annealed at $1000 \mathrm{~K}$ for at least $5 \mathrm{~min}$ in order to remove damage caused by sputtering.

The metal foils were treated in the reaction chamber in 0.5 Torr $\mathrm{C}_{2} \mathrm{H}_{4}$ (Messer Griesheim, research grade purity) for $5 \mathrm{~min}$, at 325,525 or $775 \mathrm{~K}$. The sample was cooled to room temperature, evacuated to about $10^{-6}$ Torr, and next transferred into the main chamber for AES and SIMS analysis. Hereafter, the sample was prepared for a subsequent experiment by applying one sputter and anneal cycle as described above.

\section{RESULTS AND DISCUSSION}

\section{Surface composition of the PtRh alloy}

Surface and bulk composition of the clean, equilibrated PtRh alloy were determined from the intensities of the Pt Auger transitions at 64, 168, and $1967 \mathrm{eV}$ in the spectra of PtRh alloy and Pt metal, by using the Gallon model. ${ }^{14,15}$ Backscattering factors for the three Pt transitions in the alloy and in the metal have been calculated with the empirical relation proposed by Reuter, ${ }^{16}$ see Table 1.

Application of the Gallon model requires knowledge of the monolayer intensities, defined as the relative contribution of the surface layer to the Auger spectrum of the clean metal. The monolayer intensities (Table 1) were calculated from the empirical expression for the inelastic mean free path of electrons in solids proposed by Seah and Dench. ${ }^{17}$ As surfaces of polycrystalline specimens consist mainly of the most densely packed crystallographic planes, the interlayer spacing of $\mathrm{Pt}$ (111) planes has been used, the calculations resulted in a bulk content of 62 at $\%$ and a content of the uppermost atomic layer of $84 \pm 5$ at $\% \mathrm{Pt}$. Hence, the surface of our clean, equilibrated PtRh foil is enriched in Pt.

Surface segregation of $\mathrm{Pt}$ in PtRh has been reported by Holloway and Williams ${ }^{18}$ and Williams and Nelson ${ }^{19}$ for the (111) surfaces of various PtRh single crystals with different bulk compositions, and by van Delft and Nieuwenhuys $^{20}$ for the $(100)$ surface of a Pt(0.25)Rh(0.75)single crystal. Ahmad and Tsong, ${ }^{21}$ on the other hand, reported surface enrichment of Rh in PtRh alloys, irrespective of the bulk composition. It should be noted, however, that the surface of the PtRh samples used by these authors was contaminated by a

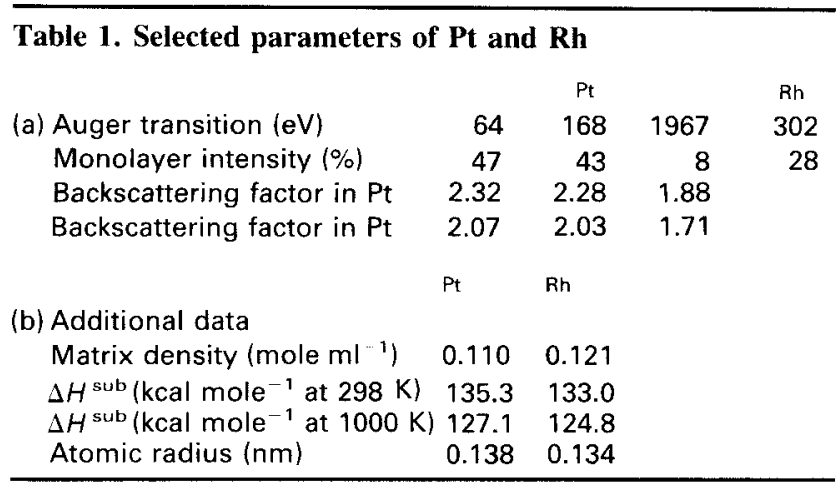

fraction of a monolayer of sulphur. All results on the surface composition of PtRh alloys are summarized in Fig. 1.

Theory does not provide a clear answer about surface segregation in PtRh. As the thermodynamic data in Table 1 show, the heat of sublimation, $\Delta H^{\text {sub }}$, of $\mathrm{Rh}$ is $2.3 \mathrm{kcal}$ mole $^{-1}$ less than that of $\mathrm{Pt}$ in the temperature range of $298 \mathrm{~K}$ to $1000 \mathrm{~K}$, and a slight enrichment of $\mathrm{Rh}$ at the surface might be expected. However, as the difference in $\Delta H^{\text {sub }}$ is small, and, moreover, the difference in atomic size between $\mathrm{Rh}$ and $\mathrm{Pt}$ is only $3 \%$ (Table 1 ), the driving force for surface segregation due to these effects is small. In such cases other effects, such as differences in surface entropy, or, perhaps, the presence of undetected impurities, may play a decisive role.

In conclusion, the surface of the clean, equilibrated $\mathrm{PtRh}$ alloy used in the present study consists of about $84 \% \mathrm{Pt}$ and $16 \% \mathrm{Rh}$. Of course, this composition may be different when the surface is covered by an adsorbate layer.

\section{AES of carbonaceous layers on Pt, Rh, and PtRh.}

Auger spectra of the clean, equilibrated Rh, PtRh, and $\mathrm{Pt}$ foils, and of the foils after treatment in $\mathrm{C}_{2} \mathrm{H}_{4}$ at different temperatures are shown in Fig. 2, along with the carbon coverage, $\theta_{\mathrm{c}}$, of the sample. The amount of carbon on the foils has been calculated in the following way. For $\mathrm{C}_{2} \mathrm{H}_{4}$ on $\mathrm{Rh}$ metal, $\theta_{\mathrm{c}}$ was estimated from the attenuation of the $\mathrm{Rh} 302 \mathrm{eV}$ peak with respect to that of the clean metal. In this procedure, the exponential attenuation model, using the effective adsorbate layer thickness and the inelastic mean free path of electrons in the adsorbate layer, was applied. According to the empirical relation of Seah and Dench ${ }^{17}$, the inelastic mean free path of electrons in a carbon matrix can be calculated to be $0.65 \mathrm{~nm}$. Previous time dependent experiments indicated the effective monolayer thickness of a carbonaceous adsorbate to be $0.11 \mathrm{~nm} .^{8}$

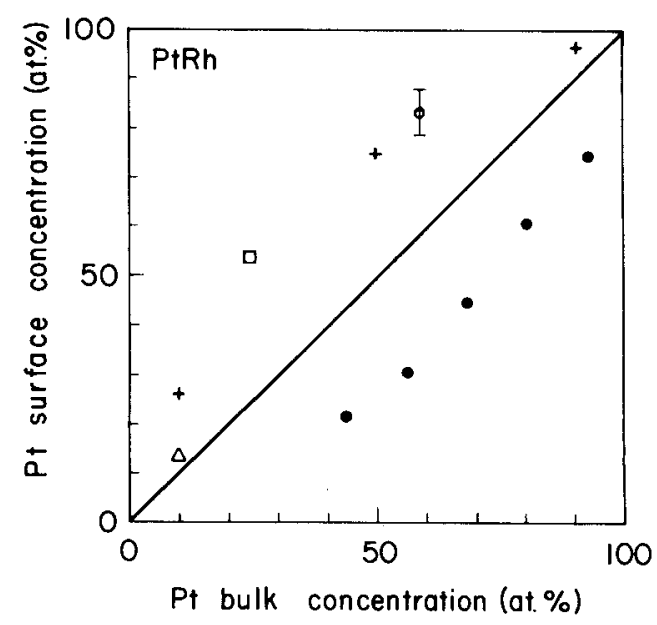

Figure 1. The composition of the uppermost atomic layer of PtRh alloys as a function of their bulk composition for various equilibration temperatures: $\bigcirc=$ present results, $1000 \mathrm{~K} ; \triangle=$ Holloway and Williams; $1000 \mathrm{~K}(\mathrm{AES}){ }^{18}+=$ Williams and Nelson, $1300 \mathrm{~K}$ (ISS) $;{ }^{19} \square=$ Van Delft and Nieuwenhuys, $1200 \mathrm{~K}$ (AES/Selective chemisorption; ${ }^{20}=$ Ahmad and Tsong, 1000 $\mathrm{K}$ (Atom probe). ${ }^{21}$ 


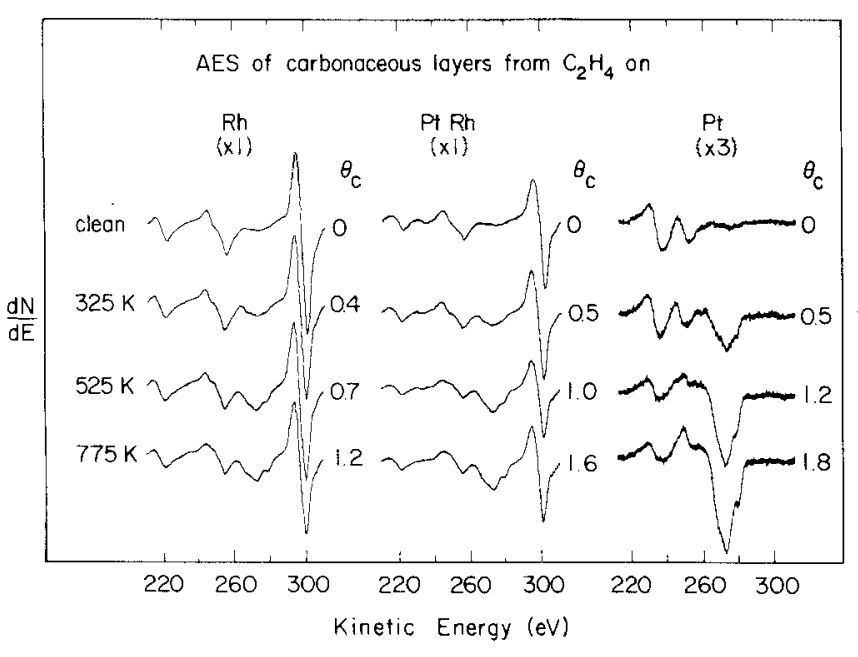

Figure 2. Differential Auger spectra of clean and ethylenetreated $\mathrm{Pt}, \mathrm{PtRh}$ and $\mathrm{Rh}$. All reactions were carried out in $0.5 \mathrm{Tor}$ $\mathrm{C}_{2} \mathrm{H}_{4}$ for $5 \mathrm{~min}$ at the temperature indicated.

Taking into account the angle of acceptance of the analyzer $\left(45^{\circ}\right)$, and assuming a layer by layer growth of the adsorbate, the attenuation of the intensity of the $\mathrm{Rh}$ $302 \mathrm{eV}$ Auger transition due to the presence of one and two monolayers of adsorbed carbon can be calculated; for uncompleted layers a linear interpolation between completed layers was used.

In the case of $\mathrm{Pt}, \theta_{\mathrm{c}}$ has been derived from the intensity ratios of the $\mathrm{C} 274 \mathrm{eV}$ and the $\mathrm{Pt} 237 \mathrm{eV}$ Auger peaks. It was assumed that an intensity ratio $C$ $274 / \mathrm{Pt} 237=2.8$ corresponds to monolayer coverage. ${ }^{1}$ After corrections for differences in the backscattering factor of both substrates (according to Reuter ${ }^{16}$ ), the intensities of the various carbon Auger transitions on both pure metals could be compared. These corrected intensities were in good agreement with trends in the $\theta_{c}$ values, calculated. The method of the attenuation of the clean substrate signal and of the ratio of the adsorbate to substrate intensities cannot be used on the PtRh alloy, since the composition of the uppermost atomic layer of the latter may change as soon as hydrocarbons are adsorbed on the surface. Therefore, $\theta_{\mathrm{c}}$ values on the alloys were calculated by comparing the corrected intensities of the $\mathrm{C} 274 \mathrm{eV}$ peak. In these calculations effects due to the presence of different carbon species have been neglected. Of course, this is a serious simplification, and. hence, the $\theta_{\mathrm{c}}$ values can only be considered as estimates.

The $\theta_{c}$ values shown in Fig. 2 indicate that for all samples the amount of carbon deposited from 0.5 Torr $\mathrm{C}_{2} \mathrm{H}_{4}$ increases with increasing temperature. Notice, that the amounts of carbon deposited at temperatures of 525 and 775 are significantly higher for $\mathrm{Pt}$ than for $\mathrm{Rh}$, whereas the $\mathrm{PtRh}$ alloy takes an intermediate position. On the assumption that the $\theta_{c}$ values of the carbonaceous deposit on PtRh formed at 525 and $775 \mathrm{~K}$ reflect the composition of the alloy surface, we find a $\mathrm{Pt}$ content of $63 \pm 10 \mathrm{at} \%$. This is much closer to the bulk composition than the surface composition of the clean alloy. Dynamic chemisorption experiments, which will be reported elsewhere, showed an unexpectedly rapid decrease of the Pt $64 \mathrm{eV}$ Auger peak intensity as soon as the alloy was exposed to $\mathrm{CH}_{4}$. In contrast to this, the decrease of the Rh $302 \mathrm{eV}$ peak was less pronounced, also after appropriate corrections for the differences in escape depth of the Pt 64 and Rh $302 \mathrm{eV}$ Auger electrons. These results suggest that surface enrichment of $\mathrm{Pt}$ in PtRh becomes less pronounced when the alloy is covered by a carbonaceous overlayer. The usual way to derive information on the nature of carbon from its Auger spectrum is to study the fine structure of the carbon spectrum between 240 and $260 \mathrm{eV}$. Unfortunately, this part of the spectrum is disturbed by the $256 \mathrm{eV}$ transition of $\mathrm{Rh}$ and the 237 and $251 \mathrm{eV}$ transitions of Pt. Spectrum subtraction techniques ${ }^{8}$ did not yield satisfactory results for the carbon-covered PtRh alloy, most likely due to differences in the surface composition between the clean and the carbon covered alloy, as discussed above.

However, the fine structure in the carbon spectra between 260 and $285 \mathrm{eV}$ contains also information on the nature of the carbon. As Fig. 2 shows, three distinct features appear in the spectrum between 260 and 285 $\mathrm{eV}$. Two of these are located at $268.8 \pm 0.4$ and 273.6 $\pm 0.4 \mathrm{eV}$ on all samples. The relative intensity of the $268.8 \mathrm{eV}$ peak decreases with increasing reaction temperature at which the carbonaceous layer was formed. In agreement with previous work ${ }^{8}$ we suggest that the $268.8 \mathrm{eV}$ peak is characteristic of carbidic or molecular carbon species which are reactive toward hydrogen. The third feature is located at $277-280 \mathrm{eV}$. The exact position varies somewhat with the reaction temperature and with the substrate. This peak has been observed before in Auger spectra of graphitic overlayers on $\mathrm{Ir},{ }^{22} \mathrm{Pt},{ }^{23.8} \mathrm{Rh},{ }^{8}$ and $\mathrm{Fe},{ }^{24}$ but it is absent in the spectrum of pure graphite. It is likely, therefore, that the $277-280 \mathrm{eV}$ peak represents the interaction of graphitic carbon with the substrate, similarly as has been proposed for carbonaceous adsorbate layers on $\mathrm{Fe}(100){ }^{24}$

In conclusion, the Auger spectra of Fig. 2 show that the carbonaceous layer formed on $\mathrm{Rh}, \mathrm{Pt}$, and $\mathrm{PtRh}$ at lower temperatures consists of carbidic and/or molecular carbon species, whereas at higher temperatures carbon of a more graphitic nature is formed. Pt is more sensitive to formation of graphitic carbon than Rh; the PtRh alloy behaves intermediate. The Auger results provide a useful background for the interpretation of the SIMS results which will be discussed hereafter.

\section{SIMS of carbonaceous layers on $\mathrm{Pt}, \mathbf{R h}$, and PtRh}

As a representative example we show in Fig. 3 the positive and negative SIMS spectra of the PtRh foil which has been exposed to $\mathrm{C}_{2} \mathrm{H}_{4}$ at $325 \mathrm{~K}$ for 5 mins. Results of the other experiments are shown in a more condensed form in Fig. 4.

The positive SIMS spectrum in Fig. 3 shows peaks at atomic mass units (amu) 12,13,14, and 15, corresponding to $\mathrm{C}^{+}, \mathrm{CH}^{+}, \mathrm{CH}_{2}^{+}$, and $\mathrm{CH}_{3}^{+}$, and peaks in the range $24-29$, corresponding to $\mathrm{C}_{2}^{+}, \mathrm{C}_{2} \mathrm{H}_{2}^{+}, \mathrm{C}_{2} \mathrm{H}_{3}^{+}$or $\mathrm{Al}^{+}, \mathrm{C}_{2} \mathrm{H}_{4}^{+}$or $\mathrm{CO}^{+}$, and $\mathrm{C}_{2} \mathrm{H}_{5}^{+}$. Unfortunately, not all peaks in the $\mathrm{C}_{2} \mathrm{H}_{n}^{+}(n=0,1, \ldots, 5)$ can be assigned unambiguously to one species. Both $\mathrm{Al}^{+}$and $\mathrm{C}_{2} \mathrm{H}_{3}^{+}$ appear at $27 \mathrm{amu}$. As, for example, a chromel-alumel thermocouple has been used, the presence of $\mathrm{Al}^{+}$in 


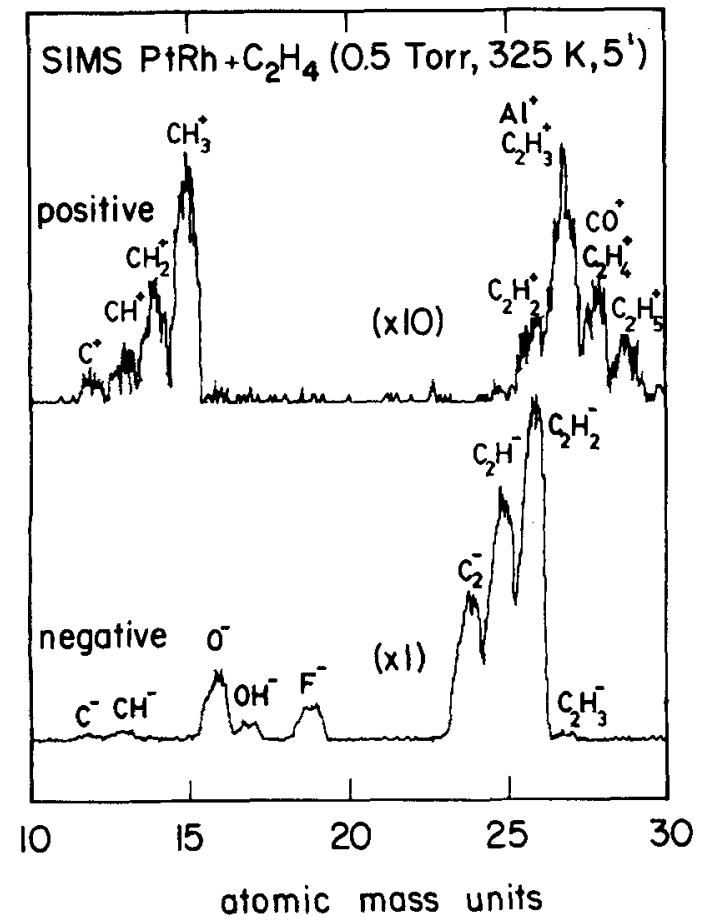

Figure 3. Positive and negative SIMS of PtRh treated in 0.5 Torr $\mathrm{C}_{2} \mathrm{H}_{4}$ at $325 \mathrm{~K}$ for $5 \mathrm{~min}$.

the SIMS spectra cannot be excluded. The peak at 28 amu can be due to either $\mathrm{C}_{2} \mathrm{H}_{4}^{+}$or $\mathrm{CO}^{+}$, the latter being a main constituent of residual gases in vacuum systems. In view of these considerations, we will only use the
SIMS peaks at masses 12-15 and 24-26, which are truly representative of hydrocarbon fragments.

The most intense peaks of the negative SIMS spectrum correspond to $\mathrm{C}_{2}^{-}, \mathrm{C}_{2} \mathrm{H}^{-}$, and $\mathrm{C}_{2} \mathrm{H}_{2}^{-}$ions at amu 24-26. The intensities in this range are typically 50 times larger than those of the $\mathrm{CH}_{n}^{-}(n=0-3)$ ions. Note that the spectrum contains contributions due to $\mathrm{O}^{-}$, $\mathrm{OH}^{-}$, and $\mathrm{F}^{-}$ions, at amu 16,17 , and 19, also. As the corresponding Auger peaks could not be detected, we believe that oxygen and fluorine are present in trace amounts which appear owing to their high sensitivity in SIMS. ${ }^{12}$

The SIMS patterns of the $\mathrm{CH}_{n}$ and $\mathrm{C}_{2} \mathrm{H}_{n}$ ions are sensitive for the nature of the carbonaceous deposit formed from $\mathrm{C}_{2} \mathrm{H}_{4}$ at different temperatures. To illustrate this we show the distributions of intensities within the four ranges of the positive and negative $\mathrm{CH}_{n}$ and $\mathrm{C}_{2} \mathrm{H}_{n}$ ions in Fig. 4. Note that the sum of the ion yields within each range has been set equal to $100 \%$, and that, as a consequence, absolute comparisons between different ranges cannot be made.

In order to investigate if the $\mathrm{Ar}^{+}$ion current density used in the experiments, $50 \mathrm{nA} \mathrm{cm}^{-2}$, gives rise to damage which may have influenced the results, the yields of selected ions were followed as a function of time during a SIMS measurement. It appeared that, although the yield of almost all ions decreased somewhat with time of exposure to the $\mathrm{Ar}^{+}$beam, correction for this result would not alter the picture as presented in Fig. 4 very much. Time-dependent experiments will be presented in a future publication. ${ }^{25}$

The positive SIMS spectra in the 12-15 mass range of the adsorption at $525 \mathrm{~K}$ on all substrates indicate the presence of a surface species containing methylgroups,

\section{Carbonaceous layers from $\mathrm{C}_{2} \mathrm{H}_{4}$ on $\mathrm{Rh}, \mathrm{PtRh}$ and $\mathrm{Pt}$ positive SIMS negative SIMS}

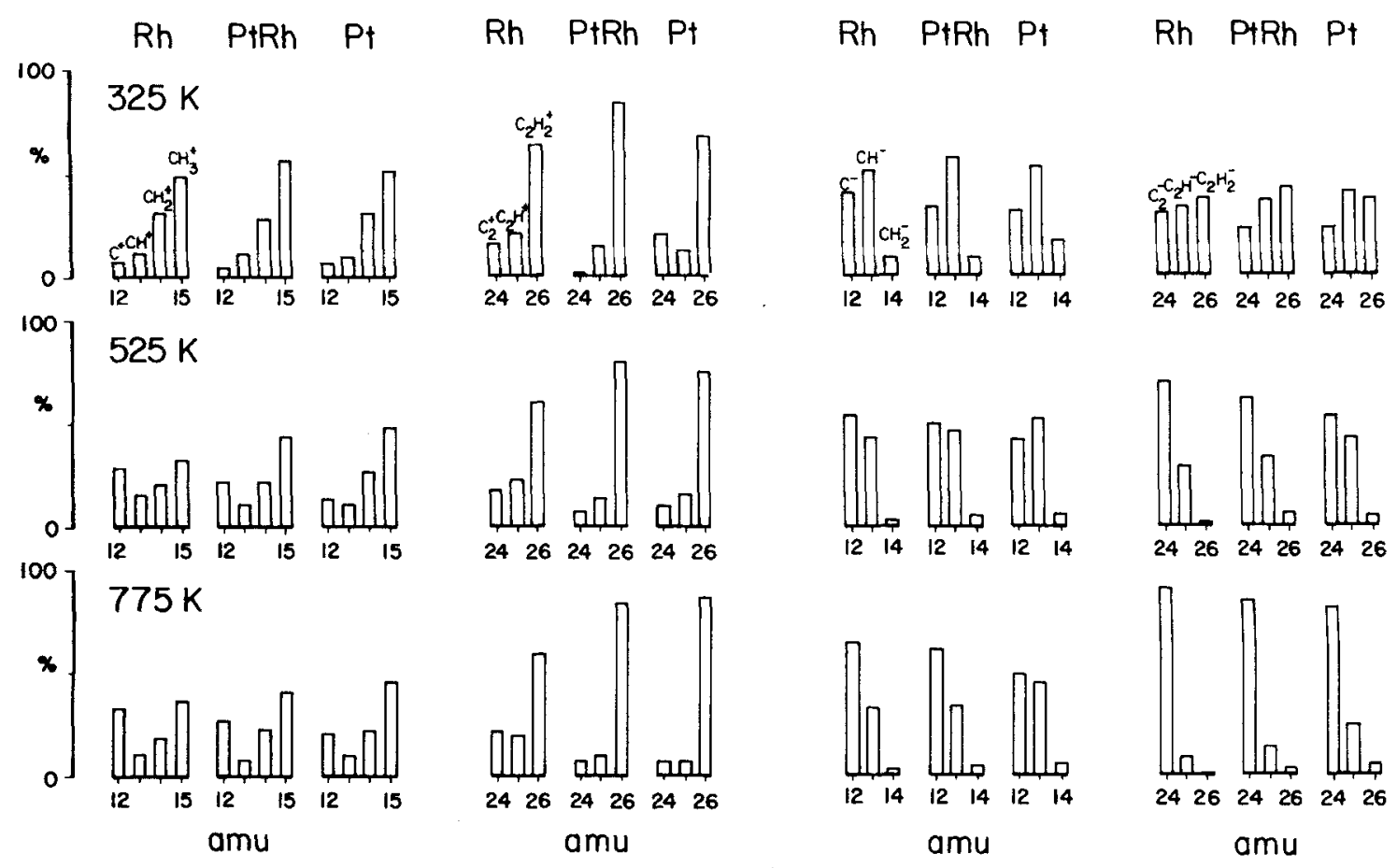

Figure 4. Distribution of intensities of positive and negative ions in the mass ranges 12-15 and 24-26 of $P t, P t R h$ and $\mathrm{Pt}$ after treatment in 0.5 Torr $\mathrm{C}_{2} \mathrm{H}_{4}$ for $5 \mathrm{~min}$ at the temperatures indicated. 
such as ethylidyne, in agreement with results of Creighton and White, ${ }^{26}$ and Wang et al. ${ }^{27}$

The SIMS results in Fig. 4 indicate that the properties of the carbonaceous deposit depends strongly on the temperature of formation and less on the substrate. The distribution of ions in each group of hydrocarbon fragments shows that the hydrogen content of the carbonaceous deposit decreases with increasing temperature of deposition. Comparison of absolute SIMS data showed that secondary ion yields from graphitic carbon are substantially lower than those of adsorbed hydrocarbons or reactive $\mathrm{C}_{x} \mathrm{H}_{4}$ fragments formed at 325 and $525 \mathrm{~K}$, respectively. ${ }^{25}$ Hence, the actual hydrogen content of the graphitic carbon will be lower than suggested by the relative intensities of the $\mathrm{CH}_{n}$ and $\mathrm{C}_{2} \mathrm{H}_{n}$ ions.

Since graphitization of carbon occurs through polymerization of smaller hydrocarbon fragments, the graphitic nature of the carbonaceous deposit will be reflected in the intensity ratio of the $C_{4}^{-}$and $C_{2}^{-}$ions (data not shown). In the case of $\mathrm{Pt}$ which, as is concluded from the Auger spectra in Fig. 2, is sensitive to formation of graphitic carbon, the $\mathrm{C}_{4}^{-} / \mathrm{C}_{2}^{-}$ratio increases from 0.01 for carbon deposited at $325 \mathrm{~K}$ to 0.05 for carbon deposited at $775 \mathrm{~K}$. For $\mathrm{Rh}$, the $\mathrm{C}_{4}^{-} / \mathrm{C}_{2}^{-}$ ratio increases from 0.01 to less than 0.02 , for carbon deposited at 325 and $775 \mathrm{~K}$, respectively. This difference in graphitization between $\mathrm{Pt}$ and $\mathrm{Rh}$ is in agreement with a discussion of Beeck. ${ }^{28}$ On PtRh the $\mathrm{C}_{4} / \mathrm{C}_{2}^{-}$ratio increases from 0.01 to 0.04 for $\mathrm{C}_{2} \mathrm{H}_{4}$ treatments at 325 and $775 \mathrm{~K}$, respectively.

As Fig. 4 shows, the mass distribution of the $\mathrm{C}_{2} \mathrm{H}_{n}^{-}$ ions is the most sensitive indicator for the state of the carbonaceous layer, followed by $\mathrm{CH}_{n}^{+}$and $\mathrm{CH}_{n}^{-}$ions, whereas the distribution of the $\mathrm{C}_{2} \mathrm{H}_{n}^{+}$ions between 24 and 26 amu contains the least information. Unfortunately, potentially interesting fragments such as $\mathrm{C}_{2} \mathrm{H}_{3}^{+}$and $\mathrm{C}_{2} \mathrm{H}_{4}^{+}$cannot be used in the present case, because of possible interference with $\mathrm{Al}^{+}$and $\mathrm{CO}^{+}$, as discussed above.

Comparison of the SIMS patterns of carbonaceous layers formed at a certain temperature on $\mathrm{Rh}, \mathrm{Pt}$, and PtRh, reveals the influence of the substrate on the nature of the carbonaceous deposit. The SIMS data in Fig. 4 show that the hydrogen content of carbonaceous deposits formed on $\mathrm{Rh}$ at 525 and $775 \mathrm{~K}$ is lower than on $\mathrm{Pt}$ at these temperatures, suggesting that $\mathrm{Rh}$ is more active for $\mathrm{C}-\mathrm{H}$ bond breaking than $\mathrm{Pt}$, in agreement with catalytic experience. ${ }^{29}$ It is also interesting to note that the SIMS patterns of carbon on PtRh differ from those on the constituent metals. The negative SIMS spectra of carbon on PtRh are more characteristic of carbon on $\mathrm{Rh}$ than on $\mathrm{Pt}$, in spite of the fact that the alloy contains $62 \% \mathrm{Pt}$.

The present work shows that SIMS spectra can be used as fingerprints for the state of carbonaceous layers on metals such as $\mathrm{Pt}$ and $\mathrm{Rh}$ and their alloys, and that the spectra reveal differences in the properties of the carbonaceous deposits on the different substrates, in agreement with Auger line shape analysis described above. The relation between the SIMS pattern and the type of hydrocarbon species on the surface will be discussed in a future publication. ${ }^{25}$

\section{Acknowledgements}

The authors are grateful to Mr. M. Hoddenbagh and Mr. W.C. van der Vleuten for technical support. J.W.N. acknowledges support from a Huygensfellowship granted by the Netherlands Organization for the Advancement of Pure Rescarch (ZWO).

\section{REFERENCES}

1. G.A. Somorjai, Chemistry in Two Dimensions: Surfaces, by. Somorjai, Cornell Univ. Press, Ithaca (1981).

2. R.R. Rye, T.E. Madey, J.E. Houston and P.H. Holloway, J. Chem. Phys. 69, 1504 (1978).

3. J.E. Houston and R.R. Rye, J. Chem Phys. 74, 71 (1981).

4. M.P. Hooker and J.T. Grant, Surf. Sci. 62, 21 (1977)

5. M.A. Smith, S. Sinharoy and L.L. Levenson, J. Vac. Sci. Techn. 16, 462 (1979).

6. F.P. Netzer, Appl. Surf. Sci. 7, 289 (1981).

7. E.G. Keim. L.L. Labohm, O.L.J. Gijzeman, G.A. Bootsma and J.W. Geus, Surf. Sci. 112, 52 (1981).

8. A.D. van Langeveld, F.C.M.J.M. van Delft and V. Ponec, Surf. Sci. 135, 93 (1983).

9. A. Benninghoven, P. Beckmann, D. Greifendorf and $M$. Schemmer, Appl. Surf. Sci. 6, 288 (1980).

10. M. Schemmer, P. Beckman, D. Greifendorf and A. Benninghoven, SIMS III, ed. by. A Benninghoven, J. Giber, J. Laszlo, M. Riedel and H.W. Werner, Springer Verlag Berlin, Heidelberg (1982)

11. H. Kaarman, B. Leidenberger, H. Hoinkes and $H$. Wisch, SIMS III, ed. by. A. Benninghoven, J. Giber, J. László, M. Riedel and H.W. Werner, Springer Verlag, Berlin, Heidelberg (1982).

12. L.L. Lauderback and W.N. Delgass, ACS Symp. Series 248, 21 (1984).

13. L.L. Lauderback and W.N. Delgass, ACS Symp. Series 279, 339 (1985).
14. T.E. Gallon, Surf. Sci. 17, 486 (1969).

15. A.D. van Langeveld and V. Ponec, Appl. Surf. Sci. 16, 405 (1983).

16. W. Reuter in: Proc. 6th Intern. Conf on X-ray Optics and Microanalysis, ed. by. G. Shinoda, W. Kohra and T. Ichinokawa, Univ. Tokyo Press (1972).

17. M.P. Seah and W.A. Dench, Surf. Interface Anal. 1, 2 (1979)

18. P.H. Holloway and F.L. Williams, Appl. Surf. Sci, 10, 1 (1982).

19. F.L. Williams and G.C. Nelson, Appl. Surf. Sci 3, 409 (1978).

20. F.C.M.J.M. van Delft and B.E. Nieuwenhuys, Surf. Sci. 162, 538 (1985).

21. M. Ahmad and T.T. Tsong, Surf. Sci. 149, L7 (1985)

22. N.A. Kholin, E.V. Rut'kov and A.Y. Tontegode, Surf. Sci. 139, 155 (1984).

23. D.W. Goodman, R.D. Kelley, T.E. Madey and J.T. Yates, J. Catal. 63, 266 (1980)

24. G. Panzer and W. Diekman, Surf. Sci. 160, 253 (1985).

25. J.W. Niemantsverdriet and A.D. van Langeveld, in preparation.

26. J.R. Creighton and J.M. White, Surf. Sci. 129, 327 (1983).

27. P.-K. Wang, C.P. Slichter and J.H. Sinfelt, J. Phys. Chem. 89, 3606 (1985)

28. O. Beeck, Disc. Farad. Soc. 8, $118(1950)$.

29. R. Merta and V. Ponec, in Proc. 4th Int. Congr. Catal. Moscow, 1968, Vol 2, p. 53, Akadémiai Kiadó, Budapest (1971). 